\title{
A methodology for monitoring globular milk protein changes induced by ultrafiltration: A dual structural and functional approach
}

\author{
M. Van Audenhaege,${ }^{*} \dagger^{1}$ J. Belmejdoub, $¥ \S$ D. Dupont, ${ }^{*} \dagger$ A. Chalvin, ${ }^{\star} \dagger$ S. Pezennec, ${ }^{*} \dagger$ Y. Le Gouar, ${ }^{\star} \dagger$ \\ F. Garnier-Lambrouin, ${ }^{*} \dagger$ M. Rabiller-Baudry, $\neq \S$ and $\mathbf{G}$. Gesan-Guiziou* $\dagger^{1}$ \\ *INRA, UMR1253 Science et Technologie du Lait et de l'œEuf, 35042 Rennes, France \\ †Agrocampus Ouest, UMR1253 Science et Technologie du Lait et de l'œEuf, 35042 Rennes, France \\ łUniversité Rennes 1, UMR6226 Sciences Chimiques de Rennes, CNRS, 35042 Rennes, France \\ §Université européenne de Bretagne, 35000 Rennes, France
}

\begin{abstract}
Understanding filtration mechanisms at a molecular level is important for predicting structural and functional properties of globular milk proteins after membrane operations. This stage is thus highly decisive for the further development of membrane separations as an efficient alternative to chromatographic processes for the fractionation of milk proteins. In this study, we proposed an original and complete analytical package for the examination of the putative effect of filtration at both macroscopic and molecular levels. We then investigated the pertinence of this analytical package during ultrafiltration (UF) of globular milk proteins in both dead-end and crossflow modes. Reverse-phase HPLC combined with statistical computing was shown to be relevant for the assessment of even slight physically induced modifications. Adaptations of circular dichroism and solubility measurements, regarding their respective dependence on temperature and $\mathrm{pH}$, were also useful for an accurate evaluation of functional modifications. At last, immunochemistry was proven to be a pertinent tool for the specific detection of modifications affecting a targeted protein, even in mixed solutions. Moreover, results obtained by such methods were shown to be coherent with data obtained from classical techniques such as fluorescence. For $\beta$-lactoglobulin, some physically induced modifications were noticed in the permeate because of shear stress inside membrane pores. In the case of $\alpha$-lactalbumin dead-end UF, permeation was shown to affect protein characteristics because of an increase in the relative calcium content responsible for a conformational transition from the apo-form to the holo-form of the protein. Finally, during crossflow UF with limited transmission of BSA, observations were coherent with a partial aggregation because of the
\end{abstract}

\footnotetext{
Received December 14, 2009.

Accepted May 22, 2010.

${ }^{1}$ Corresponding authors: genevieve.gesan-guiziou@rennes.inra.fr and marieke.vanaudenhaege@gmail.com
}

circulation of proteins in the filtration pilot. Such a hypothesis corroborates results previously mentioned in the literature.

Key words: ultrafiltration, functionality, structure, globular milk protein

\section{INTRODUCTION}

The development of functional foods, the market growth of which is estimated at 6 to $8 \% / y r$ (Lemoine, 2005 ), is mainly attributed to new potentials of enriched or purified protein fractions. For the dairy industry, the possibility of fractionating milk proteins and producing functional products with high added value was thus an important breakthrough. Currently, purified dairy protein fractions are mainly provided by chromatographic technologies, but the high cost of such fractions often prevents them from being used in targeted food applications. It therefore becomes necessary to design more attractive fractionation processes. Membrane techniques are attractive for their low environmental impact and their relatively small investment and operating costs and were shown to be appropriate for the fractionation of globular milk proteins (Roger et al., 1981; Mehra and Donnelly, 1993; Zydney, 1998). These technologies could therefore be envisaged as a good alternative or complement to current chromatographic operations. Nevertheless, the lack of fundamental knowledge concerning the effect of membrane operations on structural and functional properties of the obtained fractions limits the potentialities of such techniques in the domain of protein fractionation.

Until now, few studies have depicted the effect of filtration technologies on protein properties. Moreover, the diversity of phenomena observed in previous studies does not allow a clear understanding and prediction of milk protein structure and functionality after membrane fractionation. Putative modifications of protein functionality were mostly investigated after permeation through the membrane in crossflow or dead-end filtrations (Charm and Lai, 1971; Truskey et al., 1987; Bo- 
wen and Gan, 1992; Portugal et al., 2008). Some works conducted in crossflow mode also underlined functional modifications of proteins retained by the membrane because of high shear stress or protein concentration close to the membrane (Narendranathan and Dunnill, 1982; Mangino et al., 1988). Other studies highlighted a possible effect of shear stress on protein functionality after the passage of valves and pumps in the filtration pilot (Harris et al., 1989; Denis et al., 1990).

The comprehension of filtration processes at the molecular level is also complicated by the great heterogeneity of approaches. Most often, modifications were monitored via a single analytical technique. The evolution of functional properties was followed by measurement of the enzymatic activity (Narendranathan and Dunnill, 1982; Denis et al., 1990; Bowen and Gan, 1992), estimation of protein-surface hydrophobicity (Mangino et al., 1988; Harris et al., 1989), or study of the aggregation state (Meireles et al., 1991; Vedantham et al., 2003). Structural changes were measured via fluorescence techniques (Campbell et al., 1993; Vedantham et al., 2003; Portugal et al., 2006, 2007), circular dichroism (CD; Truskey et al., 1987; Vedantham et al., 2003), derivative UV spectroscopy (Vedantham et al., 2003), or Fourier transform infrared analysis (Maruyama et al., 2001). Because of the distinct sensitivity threshold from one analysis to the other, the use of a single technique in most studies is a large drawback for an accurate estimation of the filtration effect on protein properties. This is particularly true for globular proteins, for which an evident link is established between structure and functionality. But surprisingly, only a few studies combined structural and functional techniques (Truskey et al., 1987; Campbell et al., 1993; Portugal et al., 2006).

Except a very recent study (Portugal et al., 2007, 2008), investigations of putative structural changes linked to membrane processes were considered mostly for nondairy proteins of high pharmaceutical interest because a slight conformational change was supposed to be able to induce an immune response from the patient or to be responsible for a partial loss of biological activity (Truskey et al., 1987; Vedantham et al., 2003). However, protein modifications were pointed out to differ from one protein to the other. Because milk proteins present various configurations and structural stabilities that could lead to specific protein modifications, it becomes essential to focus on their behavior during membrane operations.

The objective of this work is thus to propose a complete analytical package to monitor both structural and functional modifications during filtration of globular milk proteins. This analytical package was developed to suit proteins that can differ according to their size, stability, aggregation state, or conformation and to highlight protein modifications occurring after either permeation through the membrane or circulation in the filtration loop.

\section{MATERIALS AND METHODS}

\section{Protein Solutions}

Three globular milk proteins of distinct size and structural properties were chosen. High purity grade bovine $\alpha$-LA ( $~ 95 \%$ purity; $M=14,200 \mathrm{~g} / \mathrm{mol}$, isoelectric point $\left.\left(\mathbf{p H}_{\mathbf{i}}\right)=4.5-4.8\right)$ was obtained from a confidential commercial origin. A slight protein contamination of this fraction by BSA and $\beta$-LG was also detected by chromatography but represented less than $6 \%$ of the total protein content. $\alpha$-Lactalbumin is a small and compact milk protein. It distances itself by an $\alpha$-helixrich structure and 2 distinct conformations because of its capacity to bind a calcium ionic entity (apo-form without calcium vs. holo-form). $\alpha$-Lactalbumin is thus considered as a metalloprotein and can specifically fix 1 calcium unit per protein molecule. Considering the high affinity constant between calcium and $\alpha$-LA (Permyakov et al., 1981), all ionic calcium was supposed to be fixed at the point saturation is reached. In these conditions, the percentage of holo- $\alpha-\mathrm{LA}$ was estimated according to the measured calcium and $\alpha$-LA concentrations. Solutions used for filtration experiments mainly comprised apo- $\alpha$-LA (without calcium) because of a $\mathrm{Ca}^{2+} / \alpha$-LA molar ratio $(\mathbf{R})$ of $0.36 \pm 0.07$. In this work, properties of the apo- $\alpha-L A$ enriched fraction $(\mathrm{R}=0.36)$ were sometimes compared with those of a holo- $\alpha$-LA solution obtained by addition of anhydrous calcium chloride up to $0.3 \mathrm{~m} M$ to a protein solution of $1.0 \mathrm{~g} / \mathrm{L}(\mathrm{R}=4.28)$. $\beta$-Lactoglobulin (L3908; 90\% purity; $\left.M=18,320 \mathrm{~g} / \mathrm{mol}, \mathrm{pH}_{\mathrm{i}}=5.1-5.4\right)$ and $\mathrm{BSA}$ (fraction V, A-2153; $96 \%$ purity; $M=66,430 \mathrm{~g} / \mathrm{mol}$; $\mathrm{pH}_{\mathrm{i}}=4.7$ ) were purchased from Sigma (St. Louis, MO). $\beta$-Lactoglobulin is a $\beta$-strand-rich protein whereas BSA mainly comprises $\alpha$ helices. Both BSA and $\beta$-LG have well-documented properties: they are characterized by their particular aggregation state (equilibrium between monomeric and dimeric states at neutral $\mathrm{pH}$ ) and the presence of a free sulfhydryl moiety. $\beta$-Lactoglobulin, $\alpha-\mathrm{LA}$, and BSA are the 3 major soluble proteins in milk; they represent 55 to 60,15 to 20 , and 5 to $6 \%$ of the soluble protein fraction, respectively.

For UF experiments, diluted protein solutions were prepared at the final concentration of $1.0 \mathrm{~g} / \mathrm{L}$ by dissolving a preweighed quantity of the protein powder in deionized water (resistivity of $18 \mathrm{M} \Omega / \mathrm{cm}$; Millipore, Billerica, MA). The concentration was adjusted by further dilution after determining the concentration with 
an Uvikon 922 UV spectrophotometer (Kontron Instruments S.A., Montigny-le-Bretonneux, France). The following extinction coefficients were used: $2.01 \mathrm{~L} / \mathrm{g}$ per centimeter for $\alpha$-LA (Kronman et al., 1964), $0.95 \mathrm{~L} / \mathrm{g}$ per centimeter for $\beta$-LG (McKenzie and Murphy, 1971), and $0.67 \mathrm{~L} / \mathrm{g}$ per centimeter for BSA (Putnam, 1975). The solutions were degassed for 20 min before filtration; the final $\mathrm{pH}$ value was equal to $6.95 \pm 0.05$ at $25^{\circ} \mathrm{C}$.

\section{UF Devices and Procedures}

As underlined in the literature, protein modifications induced by filtration operations can take place during membrane permeation or protein circulation in the filtration pilot. To distinguish between these effects, 2 distinct filtration modes were compared. Dead-end UF was used to follow protein modifications linked to permeation through the membrane. This configuration enabled us to consider only phenomena occurring at the top of the membrane, or inside the membrane pores, or both, because there was no pump or valve in the system. Crossflow UF with negligible protein permeation was suitable to focus only on protein modifications occurring during their residence time in the filtration pilot. As a result, the observed modifications could be attributed to the passage through the equipment (combining tubes, valves, and pumps) rather than through the membrane.

Dead-End Filtration. Filtration trials were performed with a 400-mL air-pressurized cell (Amicon model 8400, Millipore) providing an effective membrane area of $3.85 \times 10^{-3} \mathrm{~m}^{2}$. Flat sheet membranes (Novasep Process, Miribel, France) of distinct hydrophilic properties were used: polyethersulfone (PES) and polyacrylonitrile, which has a less hydrophobic character than PES. Membranes had a molecular weight cut-off of 30 to $40 \mathrm{~kg} / \mathrm{mol}$ and allowed the permeation of the major globular milk proteins ( $\alpha-\mathrm{LA}$ and $\beta-\mathrm{LG}$ ); in the operating conditions described below, the protein transmission was about $16 \%$ for $\beta$-LG and $45 \%$ for $\alpha-\mathrm{LA}$ and the permeated fraction was analyzed so as to depict the effect of permeation on protein structural and functional properties. Filtrations were performed at a constant transmembrane pressure $(\boldsymbol{\Delta} \mathbf{P})$ of $1.5 \times$ $10^{5} \mathrm{~Pa}$ for $7 \mathrm{~h}$ without agitation in the cell to avoid any shear stress at the top of the membrane. All experiments were carried out at $25.0 \pm 0.5^{\circ} \mathrm{C}$ using a heated water bath. In this way, filtration trials and analyses of protein properties were carried out at the same temperature. Prior to filtration, membranes were prepared as following: 1) elimination of protective agent with a double methanol rinse, 2) removal of residual methanol with a triple deionized water rinse, and 3) compaction of the membrane structure to guarantee its stability by filtration of deionized water at a $\Delta \mathrm{P}$ of $3.5 \times 10^{5}$ $\mathrm{Pa}$ for $3 \mathrm{~h}$. During protein filtration, the filtrate was collected in a beaker placed on an analytical balance (PB303-S model, Mettler-Toledo, Greifensee, Switzerland) and the filtrate mass was recorded. At the end of the experiment, transmembrane pressure was removed and the retentate was collected in the UF cell. Before storage in $0.2 \mathrm{~g} / \mathrm{L}$ of sodium azide, membranes were cleaned with $0.5 \%$ (vol/vol) P3-Ultrasil 25F (Henkel Ecolab SNC, Issy les Moulineaux, France) at $50^{\circ} \mathrm{C}$ $\left(\Delta \mathrm{P}=3.5 \times 10^{5} \mathrm{~Pa}, 30 \mathrm{~min}\right)$ under stirring, followed by thorough flushing with distilled water in the same hydrodynamic conditions. The efficiency of the cleaning procedure was regularly checked by measuring the membrane permeability with deionized water according to Darcy's law.

Crossflow Filtration. Experiments were performed with a filtration pilot described previously by Dumon and Barnier (1992). Only the screw pump was replaced by a bilobe pump. The pilot was equipped with a monotubular zirconium oxide membrane with $150 \mathrm{~kg} /$ mol molecular mass cut-off (Carbosep M1, Novasep Process, Miribel, France), 0.6-cm channel diameter, 60$\mathrm{cm}$ length, and $0.0113-\mathrm{m}^{2}$ filtering area. As previously shown by Muller et al. (2003), this cut-off led to an almost total retention of BSA in a crossflow mode. The chromatographic analysis of the permeate confirmed that protein transmission was always negligible $(<5 \%$, detection threshold of chromatography) in the conditions described below so that protein modifications detected in the feed solution were attributed to the circulation in the filtration pilot. The filtration experiments were performed with a constant crossflow velocity $(1 \mathrm{~m} / \mathrm{s})$ and constant $\Delta \mathrm{P}$ of $2.0 \times 10^{5} \mathrm{~Pa}$. Contrary to the dead-end configuration, experiments were carried out at $45 \pm$ $5^{\circ} \mathrm{C}$. Because a high temperature was shown to promote protein denaturation in the filtration pilot (Meireles et al., 1991), modifications were thus expected to be detectable even with filtration conducted at a low protein concentration. During all runs, retentate and permeate were collected and recycled to the feed tank to keep a constant concentration of the feed solution. Before storage in $0.2 \mathrm{~g} / \mathrm{L}$ of sodium azide, membranes were cleaned at $50^{\circ} \mathrm{C}$ and $\Delta \mathrm{P}=2.0 \times 10^{5} \mathrm{~Pa}$ first with $9.6 \%$ sodium hypochlorite (La Croix, Le Perray, France) and $\mathrm{NaOH}$ (Bruchet Dano, Rennes, France) at pH 13 for 1 $\mathrm{h}$ and then with $0.4 \%$ (vol/vol) P3-Ultrasil 10 (Henkel Ecolab SNC, Issy les Moulineaux, France) for $1 \mathrm{~h}$. These 2 steps were followed by thorough flushing with distilled water in the same hydrodynamic conditions. The efficiency of the cleaning procedure was regularly checked by measuring the membrane permeability with deionized water (between 2.0 and $3.5 \times 10^{5} \mathrm{~Pa}$ ) according to Darcy's law. 

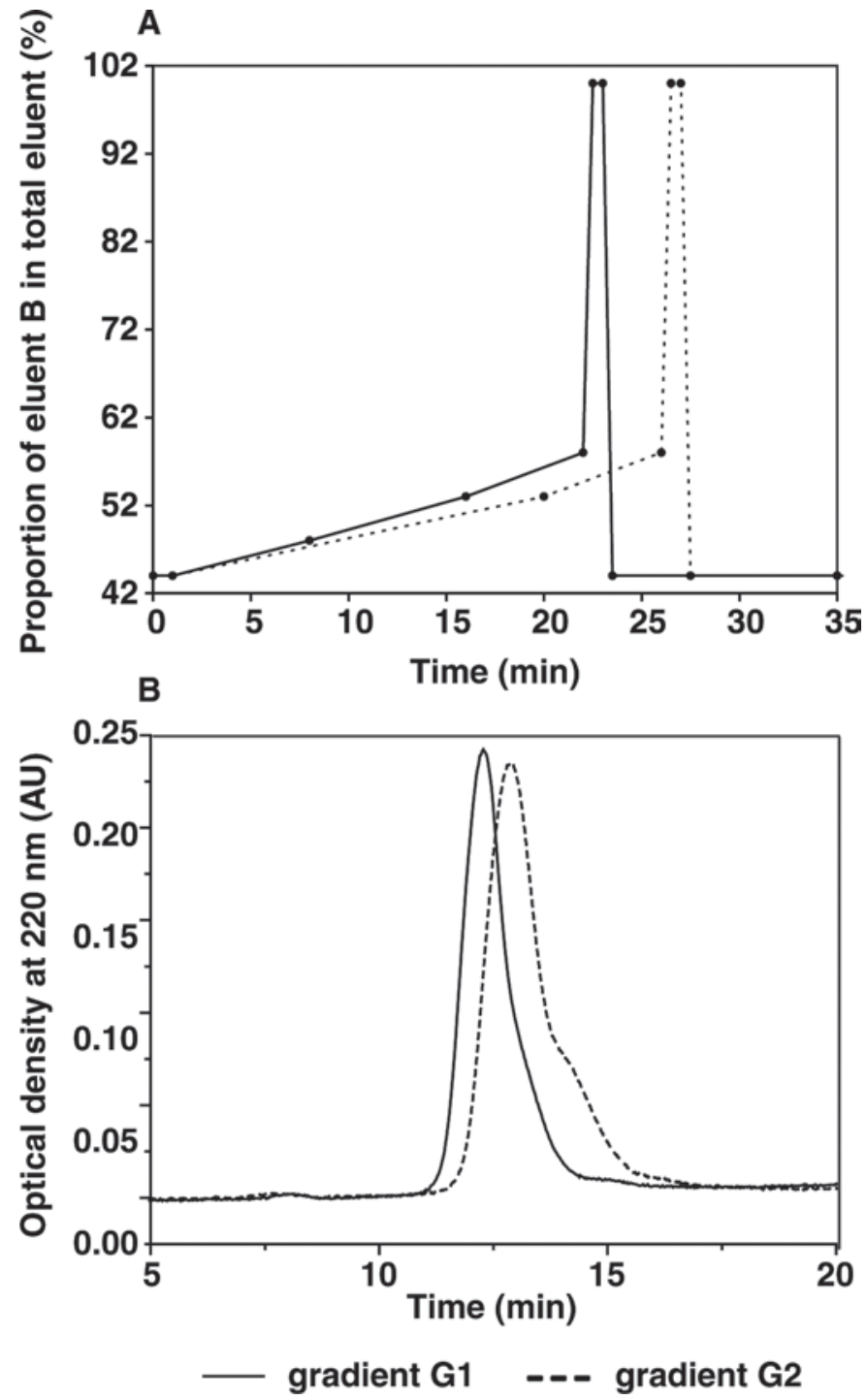

Figure 1. Analysis by reverse phase chromatography. A) Shapes of G1 and G2 elution gradients. B) Improvement of the detection for BSA subpopulations (monomeric and dimeric) with G2 compared with G1. Detailed operating conditions are given in Materials and Methods. $\mathrm{AU}=$ arbitrary units.

\section{Sample Conservation}

Because of the wide panel of analytical tests used, all structural and functional analyses could not be performed directly after filtration. Intrinsic and extrinsic fluorescence as well as immunochemical analyses studies were performed on fresh filtration samples within $3 \mathrm{~h}$ after the end of filtration. Solubility and CD measurements were carried out within $18 \mathrm{~h}$ after the end of the filtration experiment on samples kept at $4^{\circ} \mathrm{C}$. Chromatographic analyses were performed on frozen samples, but this conservation mode was previously shown to have no effect on the obtained profiles.

\section{Study of Protein Structure}

Chromatographic Analyses. Reverse phase (RP)HPLC analyses were adapted from the procedure and elution gradient shape developed by Resmini et al. (1989). Fifty microliters of samples was loaded onto a polystyrene divinylbenzene gel (PLRP-S, PS-DVB, 300 Á; $8 \mu \mathrm{m}, 150 \times 4.6 \mathrm{~mm}$ column; Polymer Laboratories, Amherst, MA) and then eluted at $1 \mathrm{~mL} / \mathrm{min}$ as a function of their apparent hydrophobicity. The eluents were $0.1 \%$ (vol/vol) trifluoro acetic acid in water (eluent A) and $0.1 \%(\mathrm{vol} / \mathrm{vol})$ trifluoro acetic acid in wateracetonitrile (20:80, vol/vol) (eluent B). Detection was performed by a diode-array UV detector at both 220 and $280 \mathrm{~nm}$. Each analysis was performed in triplicate (independent measurements) for statistical computing. Two distinct elution gradients, namely G1 and G2, were used to optimize the resolution close to the retention time of $\alpha-\mathrm{LA}$ and BSA, respectively (Figure $1 \mathrm{~A})$. The gradient G2 is characterized by a slower elution compared with the gradient G1; the percentage of acetonitrile in the eluent goes from 35.0 to $46.5 \%$ in 21 min for G1 and 25 min for G2 (Figure 1A). Detection of subpopulations, namely monomeric and dimeric species, is thus improved with G2 for a pure BSA solution (Figure 1B).

Steady-State Fluorescence. Intrinsic fluorescence scans were acquired on an LS-50B luminescence spectrophotometer (PerkinElmer, Beaconsfield, UK) by exciting the protein solutions at a wavelength of 290 $\mathrm{nm}$ so that only tryptophan residues were transferred to the excitation state. The emission of proteins from diluted samples was measured between 305 and $410 \mathrm{~nm}$ with a scan speed of $50 \mathrm{~nm} / \mathrm{min}$. Each spectrum represents the average of 3 scans and fluorescence intensity was checked to be linearly correlated to the protein concentration in the studied range (between 0.1 and $1.0 \mathrm{~g} / \mathrm{L})$.

$\boldsymbol{C D}$. Near-UV CD spectra (from 260 to $320 \mathrm{~nm}$ with a spectral resolution of $0.5 \mathrm{~nm}$ ) were recorded on a Jasco J-815 spectrometer (Jasco Inc., Easton, MD) equipped with a PTC-423S Peltier cell holder. Quartz cells with an optical path of $1.0 \mathrm{~cm}$ were used and the scan speed was $50 \mathrm{~nm} / \mathrm{min}$. Eight measurements were performed at different temperatures between 25 and $75^{\circ} \mathrm{C}$ after 3 min of equilibration and each spectrum represents the average of 3 scans. The spectra were corrected for the corresponding protein-free sample and normalized to a total protein concentration of $1.0 \mathrm{~g} / \mathrm{L}$.

Extrinsic Fluorescence. Protein surface hydrophobicity was estimated with 8-anilino-1-naphtalene sulfonate (ANS) as extrinsic fluorophore (Kato and Nakai, 1980). The interaction of the fluorescent dye ANS with protein was analyzed with an LS-50B 
fluorescence spectrophotometer (PerkinElmer) at room temperature. Fluorescence emission intensity was measured between 440 and $540 \mathrm{~nm}$, with excitation at 390 $\mathrm{nm}$ for different molar ratio between fluorophore and protein. Regardless of the solution, a linear relationship between maximum fluorescence intensity and protein concentration was proven; differences between samples can thus be easily visualized from spectra normalized at a protein concentration of $0.3 \mathrm{~g} / \mathrm{L}$.

Immunochemistry. Structural modifications induced by dead-end filtration were also assessed by surface plasmon resonance with a Biacore 3000 optical biosensor (GE Healthcare Europe GmbH, Saclay, France), and interactions between proteins and specific monoclonal antibodies (Jeanson et al., 1999) were monitored in real time. Rabbit anti-mouse IgG were covalently immobilized onto the carboxymethyl dextran matrix of a CM5 sensor chip (GE Healthcare) as described previously (Dupont et al., 2004) to capture $\alpha$-LA-specific monoclonal antibodies (anti- $\alpha-L A$ ), ensuring exposure of the monoclonal antibodies paratopes. In the binding assay, samples diluted in $10 \mathrm{~m} M$ HEPES, $3 \mathrm{mM}$ EDTA, $0.15 M$ sodium chloride, 0.005\% P20, pH 7.4 buffer (HBS-EP) at the concentration of $2 \mu \mathrm{g} / \mathrm{mL}$ were injected over the sensor surface and the association and dissociation was followed in real time. Between 2 runs, the biosensor surface was regenerated with a $5-\mu \mathrm{L}$ pulse of $10 \mathrm{~m} M$ glycine- $\mathrm{HCl}, \mathrm{pH}$ 1.7. Six different $\alpha$-LA antibodies specific from the native form of the protein were tested. Analyses were performed at $25^{\circ} \mathrm{C}$. Levels of interaction are expressed in arbitrary units named resonance units.

\section{Analysis of Functional Properties}

Solubility. Measurements of solubility were adapted from the method (ISO 15323) proposed by the International Dairy Federation (2002). Solutions with an initial concentration of $1.0 \mathrm{~g} / \mathrm{L}$ were fractionated into 8 samples and $\mathrm{pH}$ values were adjusted to the desired $\mathrm{pH}$ (between 3.0 and 8.0) by addition of small amounts of $2 \mathrm{~mol} / \mathrm{L}$ of hydrochloride acid or sodium hydroxide. A part of each sample was then centrifuged at 30,000 $\times g$ and $20^{\circ} \mathrm{C}$ for $30 \mathrm{~min}$ and the resulting supernatant fractions were filtered through Whatman No. 40 filter paper. Solubility is expressed as the ratio of total nitrogen amount between supernatant and the initial solution as determined by the Kjeldahl method (ISO 8968-1; International Dairy Federation, 2001). Results are given with an accuracy of $2 \%$.

Propensity to Aggregation or Dissociation. The aggregation state of samples was determined by size-exclusion HPLC using a gel column (TSK SuperSW3000; $4.0 \mu \mathrm{m}, 300 \times 4.6 \mathrm{~mm}$; Tosho Bioscience,
Tokyo, Japan). Protein mixtures of monomers, dimers, or oligomers, or a combination thereof, were eluted at $0.3 \mathrm{~mL} / \mathrm{min}$ with $20 \mathrm{mmol} / \mathrm{L}$ of sodium phosphate and $10 \mathrm{mmol} / \mathrm{L}$ of sodium chloride buffer $(\mathrm{pH}=6.9)$ and were detected by a diode-array UV detector at both 220 and $280 \mathrm{~nm}$.

\section{Statistical Studies}

Principal component analysis (PCA) is a simple technique that is extremely useful for identifying patterns in confusing data sets so as to highlight their similarities and differences (Jolliffe, 1986). Principal component analysis works by decomposing a matrix as the product of 2 smaller matrices, which are called loading and score matrices. Information is thus given in a new geometric space built on a few axes of maximal inertia [namely the principal components (PC)], which are linear combinations of the original variables. Because PC are orthogonal, there is absolutely no correlation between the information contained in different PC. In the case of continuous data such as spectra or chromatograms, no variance scaling is applied before the multivariate analysis. The loading plot represents the contribution of each abscissa to the first PC. As a consequence, it indicates which part of the spectrum or chromatogram is more sensitive to variations and contains most of the data set information. Score plots then represent the projection of initial spectra onto the chosen PC.

Chromatograms obtained from all RP-HPLC analyses at $280 \mathrm{~nm}$ (available in triplicate) were normalized to the same protein concentration. Principal component analysis was performed to determine whether filtration induced a significant modification of the chromatographic profile after permeation. According to the loading plot, the increase in the first $\mathrm{PC}$ value $(\mathrm{PC} 1)$ was shown to be mainly linked to a lower retention time for $\alpha$-LA.

Principal component analysis was also applied to CD spectral data obtained between 25 and $70^{\circ} \mathrm{C}$ from all experiments. As shown by the loading plot, the increase in $\mathrm{PC} 1$ can be interpreted as a progressive thermal denaturation. According to score plots, the relative PC1 contribution was thus plotted versus temperature so as to visualize differences in thermal stability between samples. Statistical analyses were conducted using the $\mathrm{R}$ software package (R Development Core Team, 2008) running on the Unix system.

\section{RESULTS AND DISCUSSION}

\section{Functional Modifications of Proteins During UF}

This work showed that some functional changes of globular milk proteins were induced during UF experi- 
ments conducted on pure protein solutions. Information collected during crossflow UF of a BSA solution performed with a $150 \mathrm{~kg} / \mathrm{mol}$ zirconium oxide membrane corroborated results described previously by Meireles et al. (1991). After a 7-h filtration and several passages in the pilot, BSA in the retentate had gained a higher propensity to aggregate as deduced from the chromatographic data (Figure 2A). The peak shoulder related to aggregates was more pronounced in the final retentate than in the initial solution, pointing out the generation of more hydrophobic species because of the circulation of proteins inside the filtration pilot. According to the ratio between monomer and dimer peak maximum intensity, about $40 \%$ of BSA was estimated to undergo aggregation in these filtration conditions. Indications of functional modifications were also noticed during $\alpha$-LA and $\beta$-LG dead-end UF. In the case of dead-end UF of a $\beta$-LG solution through a $30 \mathrm{~kg} / \mathrm{mol}$ PES membrane, only minor changes in the aqueous environment were noticed: the $\mathrm{pH}$ had slightly evolved from $7.04 \pm 0.02$ in the initial solution to $7.12 \pm 0.02$ in the permeate. The solution conductivity, which was very low in all cases, decreased from $31.1 \pm 1.0 \mu \mathrm{S} / \mathrm{cm}$ in the initial solution to $13.3 \pm 1.0 \mu \mathrm{S} / \mathrm{cm}$ in the permeated fraction. Because solutions used for filtration included mainly proteins and only a few minerals, proteins were thought to be predominant to control the conductivity of the solution. During filtration, membrane induced a partial retention of proteins (it is not the case for minerals), so the decrease in protein concentration in the permeate was responsible for the decrease in conductivity. At the same time, the extrinsic fluorescence spectrum of $\beta$-LG was increased, indicating that proteins had gained a higher surface hydrophobicity consequently to the permeation (Figure 3A). Considering the permeation of an apo- $\alpha-L A$ enriched fraction $(\mathrm{R}=0.36)$ through a $30 \mathrm{~kg} / \mathrm{mol}$ PES membrane, only slight modifications of the aqueous environment were noticed. The $\mathrm{pH}$ value of the permeate was similar to that of the initial solution (6.99 \pm 0.02 vs. $7.02 \pm 0.02$, respectively) and the slight decrease in conductivity after permeation was very low (from $30.5 \pm 1.0 \mu \mathrm{S} / \mathrm{cm}$ in the initial solution to $19.6 \pm 1.0 \mu \mathrm{S} / \mathrm{cm}$ in the permeate). As for $\beta$-LG filtration, it was most likely linked to the decrease in protein concentration because of the very low mineral content of solutions. Because of the distinct membrane selectivity toward proteins and minerals, the balance between $\alpha-\mathrm{LA}$ and ionic species was thus modified in the permeate, and especially for calcium: the $\mathrm{Ca}^{2+} / \alpha-$ LA molar ratio was significantly increased after permeation, from $0.36 \pm 0.07$ in the initial solution to $1.10 \pm$ 0.22 in the permeate. In these conditions, permeation was shown to enhance $\alpha$-LA solubility close to its isoelectric point from $90 \%$ in the initial solution to $97 \%$
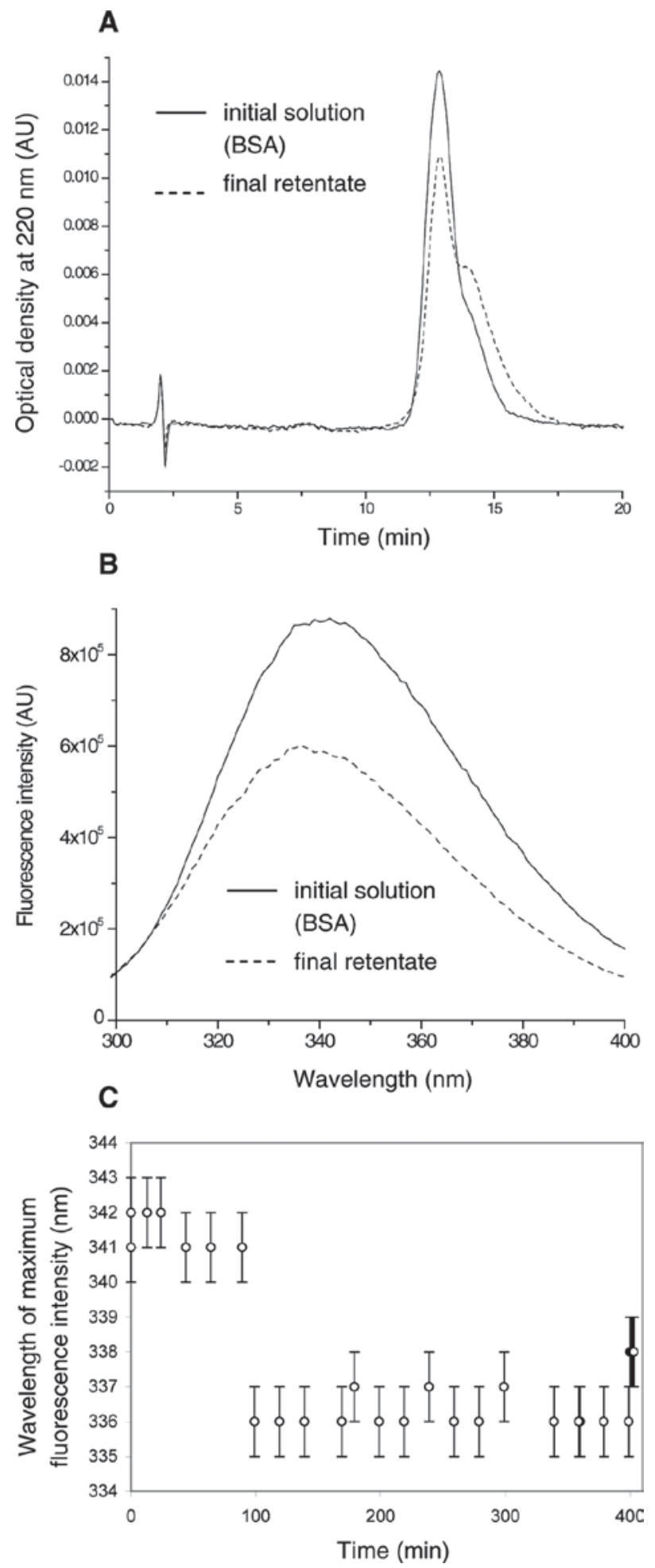

Figure 2. Structural modifications of BSA induced by crossflow UF with restricted protein transmission. A) Comparison of the chromatographic profiles of initial solution and final retentate generated by crossflow UF of a BSA solution through a $150 \mathrm{~kg} / \mathrm{mol}$ zirconium oxide membrane. B) Effect of crossflow UF onto the profile of intrinsic fluorescence in the same operating conditions. C) Progressive evolution of the wavelength of maximum fluorescence intensity during BSA circulation inside the filtration pilot. AU $=$ arbitrary units. 
in the permeated fraction (Figure 4A). Simultaneously, $\alpha$-LA surface hydrophobicity was sharply decreased as deduced from the decrease in extrinsic fluorescence maximum intensity (Figure 4B).

As illustrated by these examples, globular milk proteins can undergo functional modifications of distinct origin and intensities during both dead-end and crossflow UF. The goals of this original work were thus to select and adapt techniques susceptible to detect functional and structural changes of proteins during filtration processes and to use the analytical package proposed to enable a more objective assessment of putative protein modifications at both macroscopic and molecular levels, which is necessary for the understanding of changes observed on proteins.

First, the selection and improvement of each proposed structural or functional analysis to detect filtrationinduced modifications is explained and their capacities to monitor protein modifications are illustrated in a dead-end configuration. Then, results are compared with conventional analyses to prove the pertinence of filtration-induced modifications that were detected.

\section{Selection of Appropriate Analyses}

Appropriate techniques for monitoring structural and functional modifications of proteins were chosen by taking into account several constraints encountered during filtration. One of the greatest issues for the analysis of structural and functional properties after filtration was the limited quantity, or concentration, or both, of proteins in the filtration samples. After dead-end UF, concentration in the global permeate was approximately $0.45 \mathrm{~g} / \mathrm{L}$ for experiments conducted with $\alpha$-LA and $0.16 \mathrm{~g} / \mathrm{L}$ for those conducted with $\beta$-LG. In our study, structural properties of globular milk proteins were thus evaluated using chromatography, $\mathrm{CD}$, intrinsic fluorescence, and immunochemistry because the low protein concentration in filtration samples prevented them from being analyzed via infrared spectroscopy and light scattering. Indeed, the concentration limit of detection for the chosen techniques is below $0.5 \mathrm{~g} / \mathrm{L}$ whereas the study of protein in solution by infrared spectroscopy and light scattering is usually limited to concentrations above $10 \mathrm{~g} / \mathrm{L}$ and 1 to $2 \mathrm{~g} / \mathrm{L}$, respectively (Lefèvre and Subirade, 1999).

The small quantity of samples was also a drawback for a large investigation of functional properties. Because no usual activity test (enzymatic of specific activity) was available for globular milk proteins, functional criteria were chosen with respect to potential industrial uses. Protein solubility, propensity to aggregation or dissociation, and surface hydrophobicity were selected because of their relevance and their potential correla-

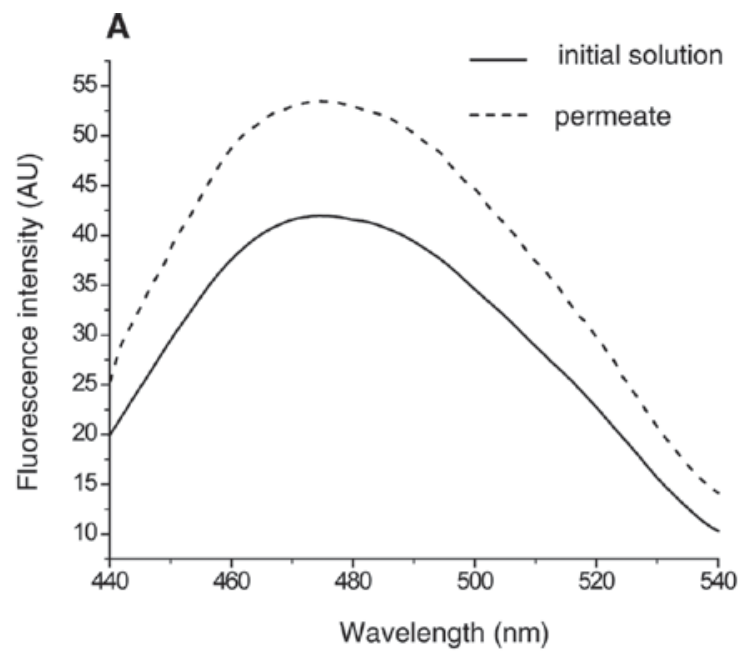

B
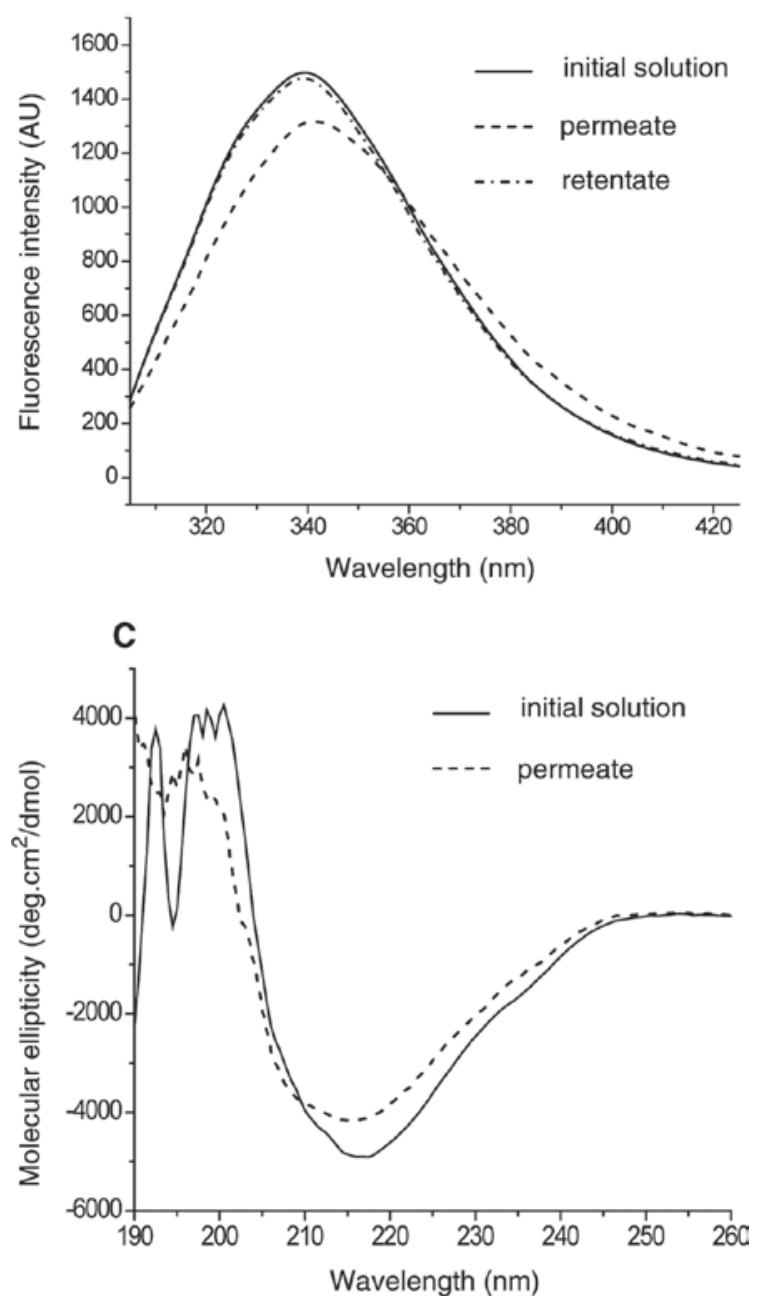

Figure 3. Modification of $\beta$-LG induced by dead-end UF. Effect of the dead-end UF of $\beta$-LG through a $30 \mathrm{~kg} / \mathrm{mol}$ polyethersulfone membrane. A) Surface hydrophobicity of $\beta-\mathrm{LG}$ for the initial solution and the final permeate as deduced from extrinsic fluorescence measurements. B) Intrinsic fluorescence spectra for the initial solution and the final permeate and retentate. C) Far-UV circular dichroism spectra for the initial solution and the final permeate. $\mathrm{AU}=$ arbitrary units. 

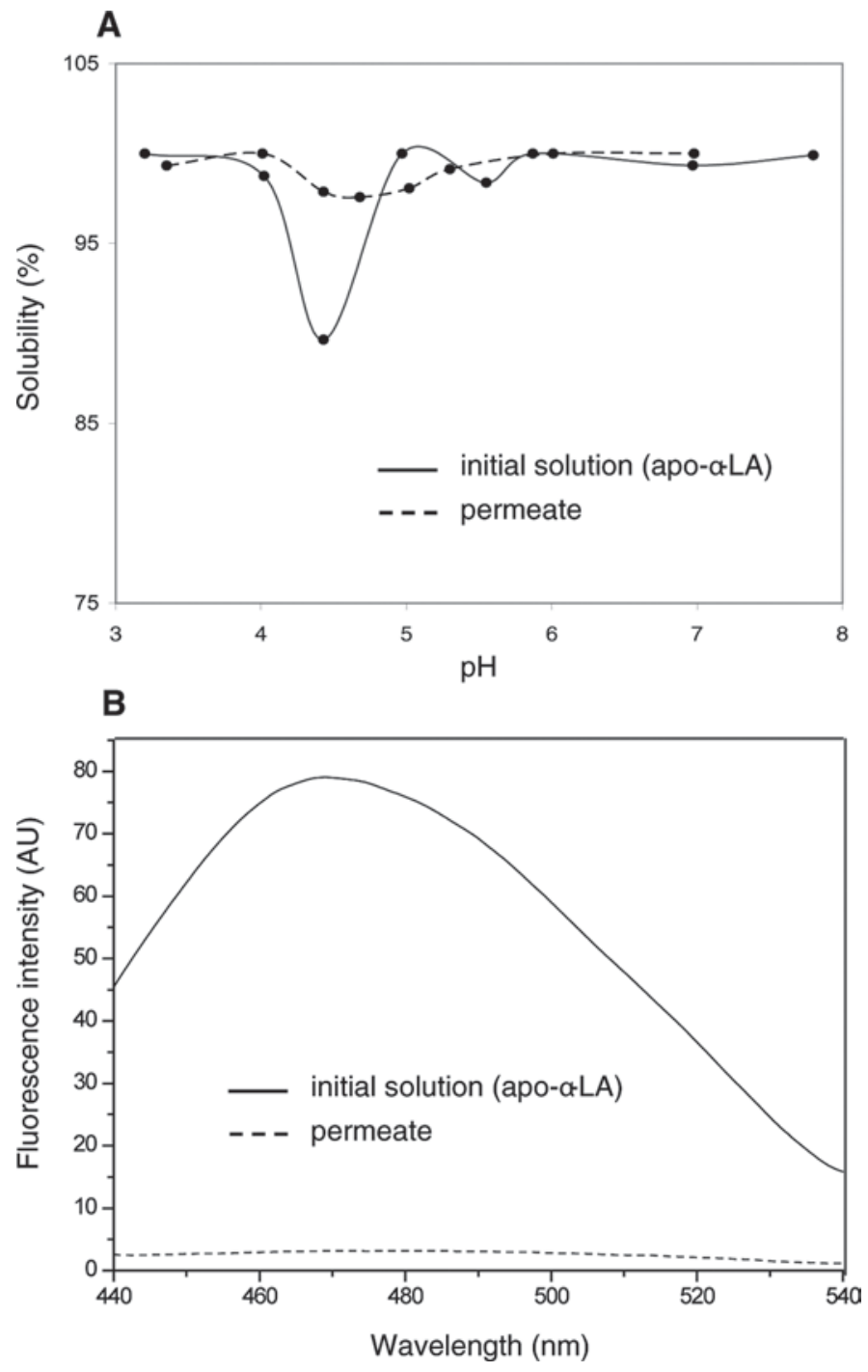

Figure 4. Functional modifications of $\alpha$-LA induced by dead-end UF. Effect of the dead-end permeation of an apo- $\alpha$-LA enriched fraction through a $30 \mathrm{~kg} / \mathrm{mol}$ polyethersulfone membrane. A) Solubility profile of $\alpha$-LA for the initial solution and the permeate. B) Surface hydrophobicity of $\alpha$-LA for the initial solution and the permeate as deduced from extrinsic fluorescence measurements. AU = arbitrary units.

tion with other protein technofunctional characteristics such as foaming or emulsifying capacities and gelling properties (Kato and Nakai, 1980; Towsend and Nakai, 1983; Mangino et al., 1988).

Another constraint was the need for a detection of both potentially low intensity and physically or chemically induced modifications. Several techniques are already widely used for the assessment of globular protein modifications having a chemical or thermal origin. Because of their high sensitivity, some of them were chosen in this study because they were expected to be responsive to even physically induced modifications such as those generated by shear stress in the filtration pilot or inside membrane pores. For instance, extrinsic fluorescence was expected to be a pertinent tool because it was recently shown to be useful for quantifying the effect of hydrodynamic shear on protein conformation change (Themistou et al., 2009). In some cases, little adaptations to standard protocols or data treatment or both were made to increase information provided by classical techniques and to get the data analysis more suitable to our case study, as developed afterward.

During filtration operations, membrane acts as a selective barrier and controls both protein and ionic contents depending on the operating conditions. Changes in protein composition and physicochemical parameters (such as $\mathrm{pH}$ and ionic strength) may then occur and have to be taken into account for the interpretation of structural and functional data of proteins from filtration samples. Sensitivity of functional analyses to $\mathrm{pH}$ and ionic strength variations are therefore described in this work for globular milk proteins.

Table 1 gives the different methods that were chosen according to these criteria. They are classified as structural or functional tools and described according to their potentials. It is important to emphasize here that a few selected techniques (RP-HPLC and immunochemistry) have protein specificity; they should therefore be used for the detection of structural modifications even in mixed or more complex solutions.

\section{Improvement of Analytical Tools}

Different modifications were applied to standard protocols so as to allow the determination and quantification of filtration-induced modifications. Reverse phase-HPLC (combined with PCA or not) enabled the detection of structural changes of BSA and $\alpha-\mathrm{LA}$. The thermal stability of proteins was checked according to a statistical treatment of near-UV CD spectra. In the case of solubility, $\mathrm{pH}$ dependency was chosen as a pertinent way to detect even slight functional modifications induced by the filtration.

RP-HPLC: A Technique Sensitive to Structural Changes. Reverse-phase chromatography is a well-documented technique for the separation and detection of globular milk proteins (Geng and Regnier, 1984; Resmini et al., 1989; Elgar et al., 2000). In this study, slight differences in RP-HPLC profiles of $\alpha$-LA before and after dead-end filtration were observed (Figure $5 \mathrm{~A}$ ) and highlighted according to a multivariate analysis (Figure 5B). In the new system of reference, the first axis (PC1) explained up to $86 \%$ of the data set variability and was mainly relative to the retention time of $\alpha$-LA on the chromatographic column. The retention time of $\alpha$-LA was decreased for the fraction 
Table 1. Potentialities of the selected analytical techniques ${ }^{1}$

\begin{tabular}{|c|c|c|c|c|c|c|}
\hline Analysis & Structure & Function & $\begin{array}{l}\text { Chemically } \\
\text { induced } \\
\text { damage }\end{array}$ & $\begin{array}{c}\text { Thermal } \\
\text { denaturation }\end{array}$ & $\begin{array}{l}\text { Physically } \\
\text { induced } \\
\text { modification }\end{array}$ & $\begin{array}{c}\text { Composition } \\
\text { /aggregation } \\
\text { state }\end{array}$ \\
\hline Reverse phase HPLC & $x$ & & ++ & - & + & ++ \\
\hline Intrinsic fluorescence & $\times$ & & ++ & + & ++ & + \\
\hline Immunochemistry & $\times$ & & ++ & ++ & ++ & + \\
\hline Circular dichroism & $\times$ & $\times$ & ++ & ++ & + & + \\
\hline Extrinsic fluorescence & $\times$ & $\times$ & ++ & + & ++ & + \\
\hline Solubility & & $\times$ & ++ & ++ & ++ & + \\
\hline Size-exclusion HPLC & & $\times$ & - & + & - & ++ \\
\hline
\end{tabular}

permeated through a PES membrane compared with the initial solution (Figure 5A). This result proved that permeation affects $\alpha$-LA interactions with the column stationary phase and thus its structural properties; RP-HPLC is therefore a pertinent tool for the detection of filtration-induced modifications of globular milk proteins even if the origin of such protein changes needs to be elucidated.

Detection of Changes in Protein Stability by Near-UV CD. Structural modifications were also monitored via spectroscopic analyses such as CD and intrinsic fluorescence. These techniques, which are known to be dependent on the aggregation state (because of light scattering generated by large protein assemblies), are appropriate in our study because all protein samples (permeates and retentates) present less than 5\% aggregates according to size-exclusion chromatography. Near-UV of far-UV CD has already been used to follow structural modifications induced by permeation (Truskey et al., 1987; Vedantham et al., 2003). However, significant modifications of spectra were visible only when the tertiary structure of more than 10 to $20 \%$ of proteins was affected (Truskey et al., 1987). As a consequence, the CD results in this work were reinforced by a study of protein thermal stability, which is known to be particularly sensitive to conformational changes of metalloproteins such as $\alpha$-LA. Multivariate analysis was chosen as an efficient tool to display a significant effect of filtration on the thermal stability of proteins because information was obtained from the entire spectrum (between 190 and $260 \mathrm{~nm}$ ). On the contrary, thermal denaturation was often followed in previous studies by considering the evolution at a single wavelength characteristic of the protein structure (e.g., $222 \mathrm{~nm}$ for an $\alpha$-helix-rich protein). This approach was validated in the case of dead-end UF of the apo- $\alpha-L A$ enriched fraction. After statistical computing, the first axis (PC1) of the new system of reference contained most of the data set information and explained more than $95 \%$ of the variability. As deduced from the loading plot, the relative contribution of PC1 between 25 and $70^{\circ} \mathrm{C}$ was shown to be representative for the thermal denaturation of proteins. After permeation of $\alpha$-LA through a PES membrane, even if near-UV CD spectra at ambient temperature were not severely modified (Figures $6 \mathrm{~A}$ and $6 \mathrm{~B}$ ), proteins were shown to have gained some thermal stability (Figure 6C). Such observations were consistent with the increase in calcium content of the permeated fraction. In fact, the apo-form (without calcium) is more rapidly destabilized by thermal treatments than the holo-form (calcium binding) even if structural analyses suggest that tertiary structures are very close for both apo- $\alpha$-LA and holo- $\alpha-$ LA (Chrysina et al., 2000). The statistical analysis of protein stability as measured by near-UV CD is thus a pertinent tool to detect slight modifications in protein characteristics after permeation.

Contribution of Solubility Measurements to the Study of Protein Functionality. So as to improve the detection threshold of functional changes, the $\mathrm{pH}$ dependence of solubility was also considered. Solubility was thus measured at 8 different $\mathrm{pH}$ values ranging from 3.0 to 8.0. In this work, a slight adaptation of the method proposed by the International Dairy Federation (2002; ISO 15323) was developed for diluted protein solutions $(1 \mathrm{~g} / \mathrm{L}$ instead of a usual concentration of $10 \mathrm{~g} / \mathrm{L}$ ) so as to suit filtration conditions. The solubility profile of the diluted $\alpha-\mathrm{LA}$ solution $(1 \mathrm{~g} / \mathrm{L})$ was close to that obtained for the concentrated solution $(10 \mathrm{~g} / \mathrm{L})$ with a solubility minimum around the isoelectric point of $\alpha-\mathrm{LA}\left(\mathrm{pH}_{\mathrm{i}}=4.5-4.8\right.$; results not shown). Data were also concordant with the literature (Kella et al., 1989; Herceg et al., 2004). Moreover, proteins were shown to have gained solubility close to their isoelectric point after permeation through a $30 \mathrm{~kg} / \mathrm{mol}$ PES membrane (Figure 4A). Such a technique is thus sensitive enough to detect modifications induced by dead-end UF. 


\section{Pertinence of Analyses in the Presence of lonic or Protein Contaminants}

Sensitivity of Fluorescence and Solubility Analyses to Physicochemical Variations. Because of the lack of information in the literature for the studied proteins, the sensitivity of the chosen structural techniques to $\mathrm{pH}$, ionic strength, and protein conformation was examined. Studied ranges of variation for $\mathrm{pH}$ (between 6.7 and 7.3) and ionic strength (from 0 to
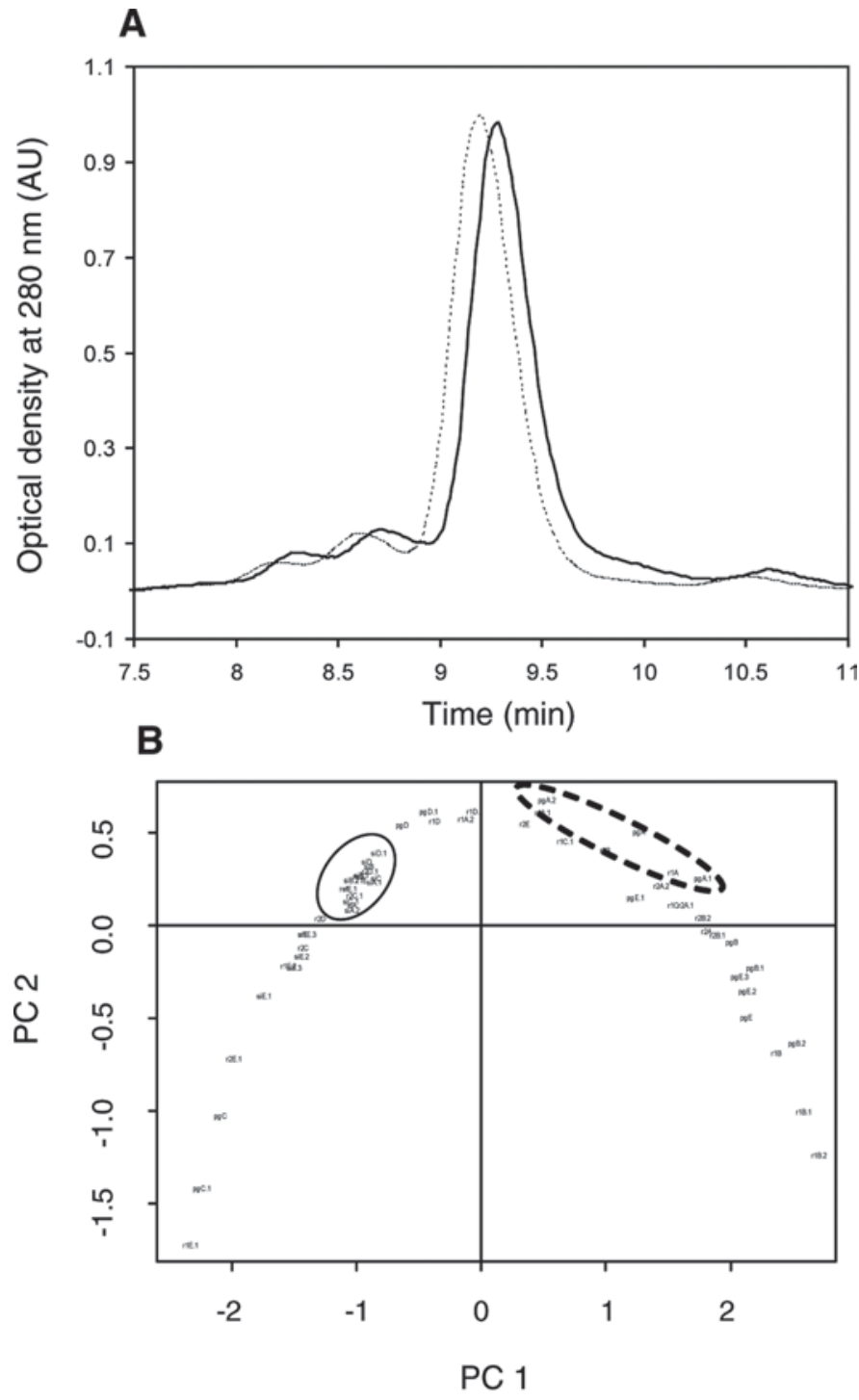

_ initial solution (apo-a-LA) - - - permeate

Figure 5. Detection of physically induced modifications of $\alpha$-LA by reverse phase chromatography. A) Decrease in $\alpha$-LA retention time after permeation through a $30 \mathrm{~kg} / \mathrm{mol}$ polyethersulfone membrane. B) Score plot of the multivariate analysis: detection of significant differences in retention times according to projections on principal component $(\mathrm{PC}) 1 . \mathrm{AU}=$ arbitrary units.
$100 \mathrm{~m} M$ of added sodium chloride) were chosen to be in the range of those observed in filtration experiments. Because $\alpha$-LA is a metalloprotein, calcium addition was also considered because it is responsible for a transition from the apo-form to the holo-form of the protein.

In the studied range of variation, $\mathrm{pH}$ and ionic strength were shown to have no effect on the shape of the emission spectra of intrinsic fluorescence for the apo- $\alpha$-LA enriched fraction (Figures 7A) and the $\beta$-LG solution (results not shown). The wavelength of maximum fluorescence intensity was, however, dependent on the protein nature or conformation at neutral $\mathrm{pH}: 334.5$ $\pm 1.1 \mathrm{~nm}$ for a holo- $\alpha$-LA solution, $337.8 \pm 1.5 \mathrm{~nm}$ for the apo- $\alpha-L A$ enriched fraction, and $339.2 \pm 0.3 \mathrm{~nm}$ for a $\beta$-LG solution.

Extrinsic fluorescence, which was chosen for the estimation of protein surface hydrophobicity, was shown to be dependent on physicochemical conditions; a decrease in $\alpha$-LA surface hydrophobicity was observed when increasing the $\mathrm{pH}$ value at low ionic strength or increasing the ionic strength at a given $\mathrm{pH}$ value (Figure 7B). However, the effect of $\mathrm{pH}$ on $\alpha$-LA surface hydrophobicity was partially erased for higher ionic strengths (Figure 7B). This technique was also dependent on the protein conformation: ANS affinity was lower for the holo- $\alpha$ LA solution than for the apo- $\alpha$-LA enriched fraction in similar experimental conditions. As illustrated in Figure $7 \mathrm{C}$, the predominant role of calcium for $\alpha$-LA surface hydrophobicity was confirmed by the measurement at different molar $\mathrm{Ca}^{2+} / \alpha-\mathrm{LA}$ ratio: at low $\mathrm{Ca}^{2+} / \alpha-\mathrm{LA}$ ratio, surface hydrophobicity of the protein was decreased while increasing the relative calcium content. On the contrary, no significant effect of $\mathrm{pH}$ and ionic strength was noticed in all tested conditions for $\beta-\mathrm{LG}$ solutions (data not shown).

Finally, the effect of ionic strength on both apo- $\alpha-L A$ enriched fraction and $\beta$-LG solubility profile was studied. With no addition of sodium chloride, the solubility minimum reflected the protein nature because each protein tended to aggregate near its isoelectric point. As a consequence, the minimum solubility was observed close to a $\mathrm{pH}$ value of 4.5 to 4.8 for $\alpha$-LA solutions and around 5.1 to 5.4 for $\beta$-LG. In addition, the solubility was shown to be higher all along the $\mathrm{pH}$ range when increasing the ionic strength. According to salting-in effects, when the quantity of available ions increased for a given protein content, the solvation of protein increased. Protein-solvent interactions were predominant on solvent-solvent interactions and the solubility was improved.

Immunochemistry: A Performing Tool for Structural Analysis in Presence of Protein Contaminants. Because of the presence of a few protein contaminants in the commercial powders and the rela- 
A

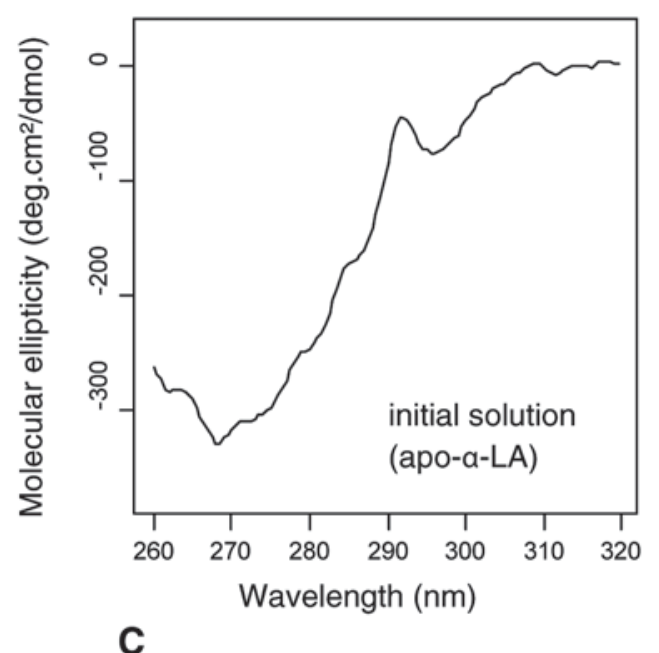

B

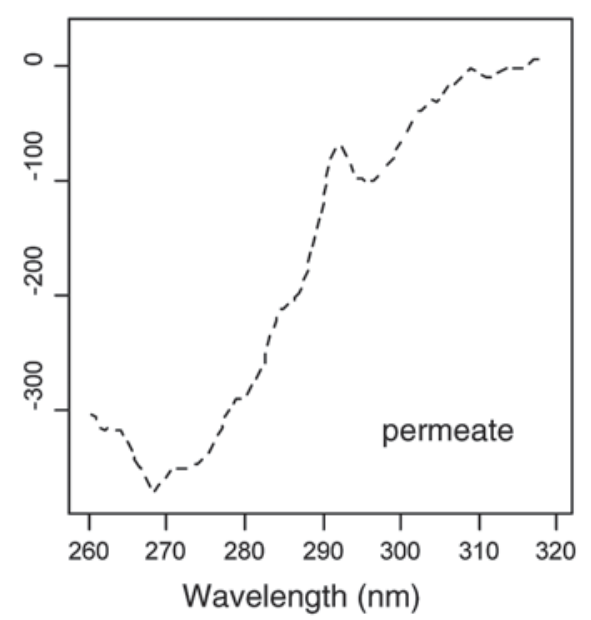

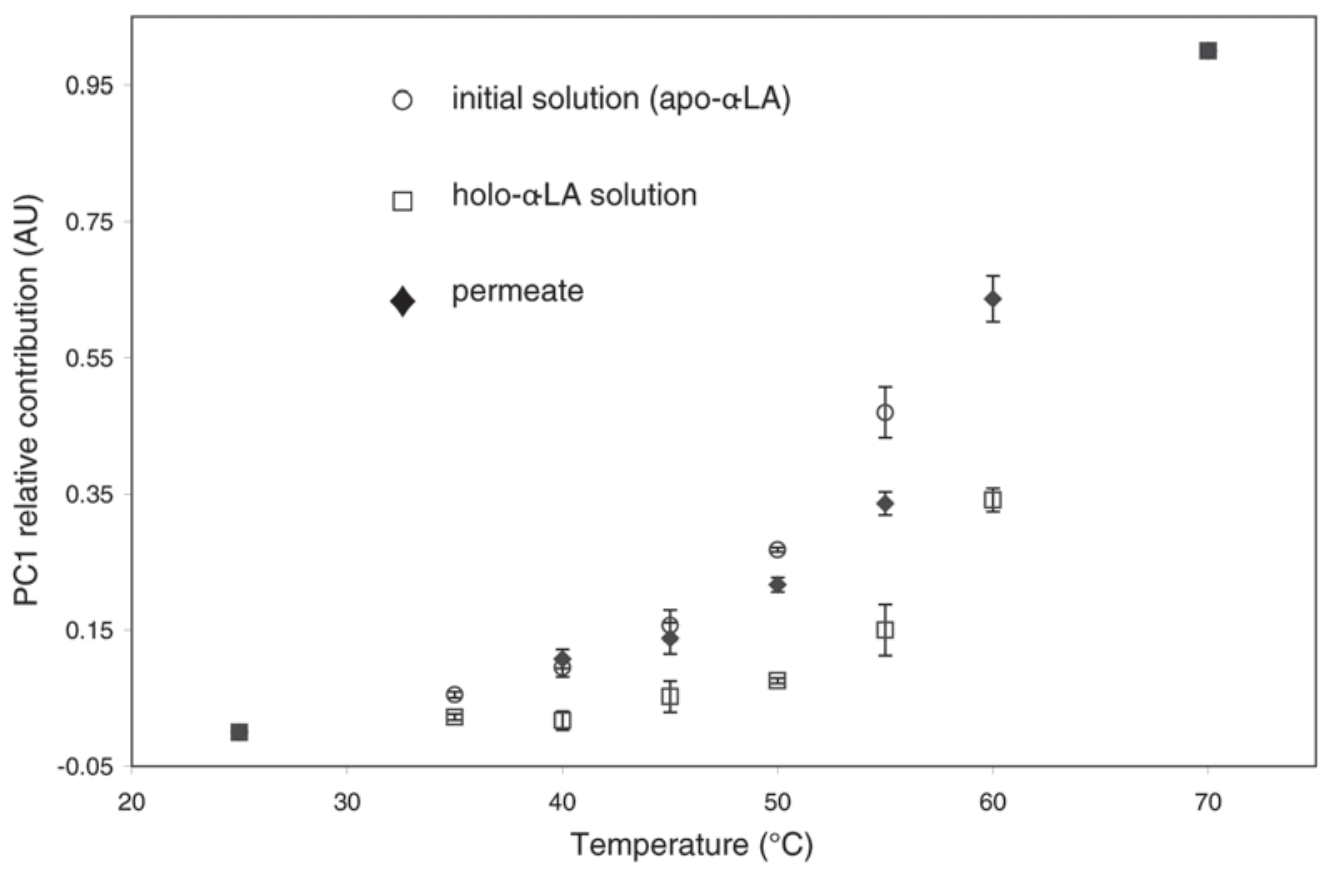

Figure 6. Detection of protein changes by near-UV circular dichroism. A and B) Spectra of $\alpha$-LA tertiary structure for, respectively, the initial apo- $\alpha$-LA enriched solution (molar $\mathrm{Ca}^{2+} / \alpha-\mathrm{LA}$ ratio of $0.36 \pm 0.07$ ) and the fraction resulting from dead-end permeation through a 30 $\mathrm{kg} / \mathrm{mol}$ polyethersulfone membrane. C) Effect of $\alpha$-LA permeation on its thermal stability according to a multivariate analysis. $\mathrm{PC}=$ principal component; $\mathrm{AU}=$ arbitrary units.

tively high membrane selectivity in some experimental conditions of dead-end UF, changes in protein composition were sometimes observed in filtration samples. As a consequence, protein composition was estimated by RP-HPLC for all samples so as to determine whether spectroscopic measurements could be affected. Immunoassays were also performed to specifically detect modifications of $\alpha$-LA structure after dead-end permeation through UF membranes. Depending on the sam- ple composition, these analyses were used in addition to or in place of spectroscopic analyses. Up until now, such an approach was nonexistent for the detection of filtration-induced changes in protein conformation.

From a general point of view, relevance of immunochemical techniques to monitor conformational changes on a protein during the filtration process highly depends on 2 major parameters. First, the reproducibility of the technique needs to be high so as to allow the detec- 


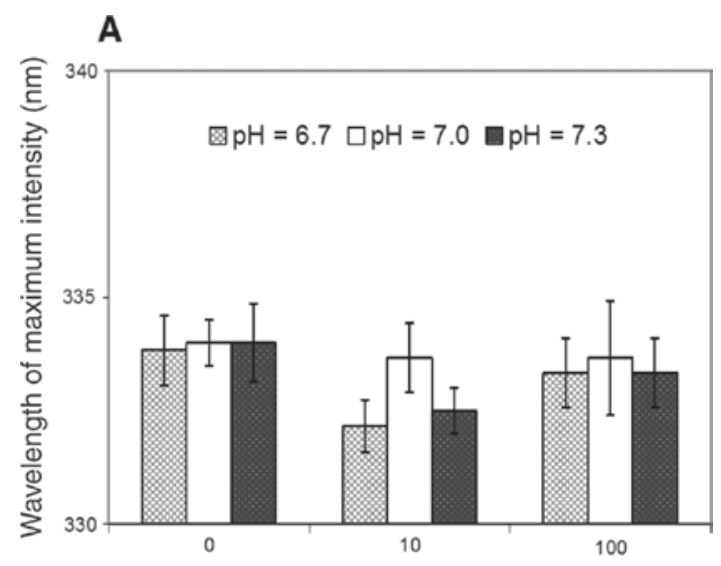

Concentration of added sodium chloride $(\mathrm{mM})$

\section{B}
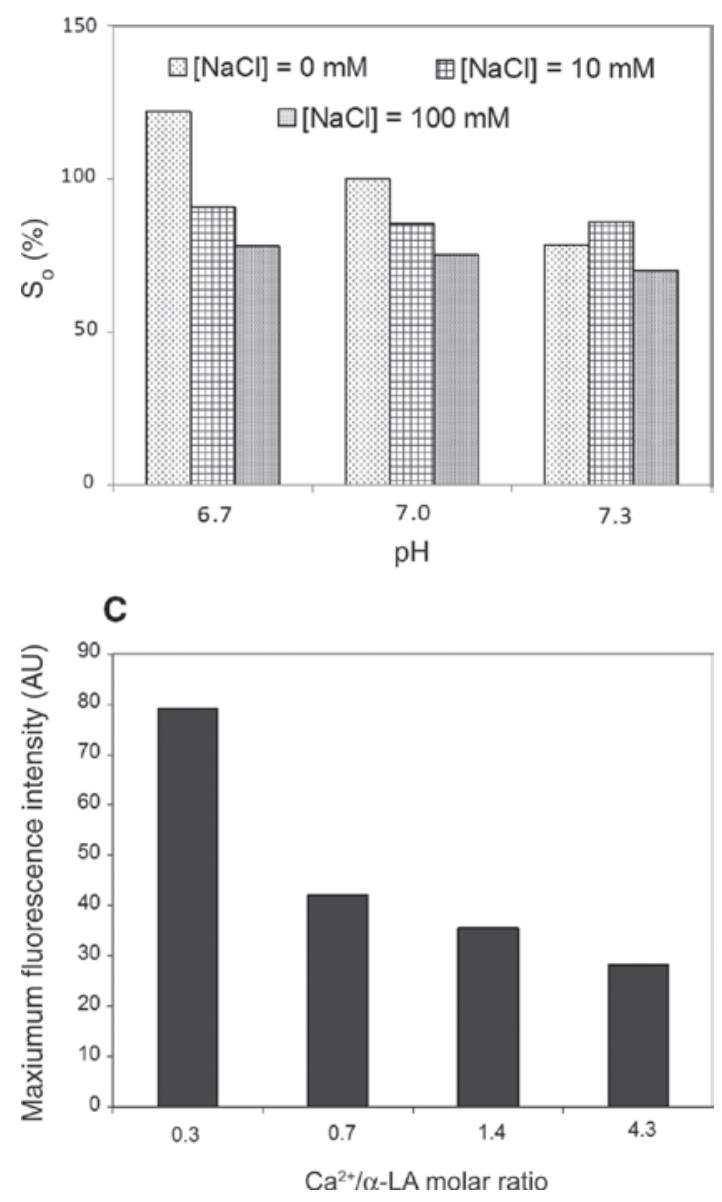

Figure 7. Sensitivity of fluorescence techniques to minor variations of $\mathrm{pH}$ and ionic strength. A) Sensitivity of intrinsic fluorescence to $\mathrm{pH}$ and ionic force for the apo- $\alpha-\mathrm{LA}$ enriched fraction (molar $\mathrm{Ca}^{2+} / \alpha-\mathrm{LA}$ ratio of $0.36 \pm 0.07)$ as deduced from the variation of the wavelength of maximum intensity. B) Sensitivity of extrinsic fluorescence to $\mathrm{pH}$ and ionic force; $\mathrm{S}_{0}$ represents the slope of maximum fluorescence intensity as a function of apo- $\alpha-\mathrm{LA}$ concentration and values are compared with the value obtained in reference conditions $(\mathrm{pH}=7.0$ and no added salt). C) Effect of the $\mathrm{Ca}^{2+} / \alpha-\mathrm{LA}$ molar ratio onto protein surface hydrophobicity as estimated by the maximum extrinsic fluorescence intensity. $\mathrm{AU}=$ arbitrary units. tion of slight conformational changes on the molecule. As a consequence, we chose to use the $\alpha$-LA specific antibodies on a Biacore (interassay CV: 3 to $5 \%$ ) rather than on an ELISA (interassay CV: 15 to 20\%) format. Second, it is important to consider the specificity of the antibody used. Because monoclonal antibodies react with only 1 antigenic site at the surface of the protein, an antibody specific from a conserved region will not allow the detection of any structural modification of the target protein. We then used a panel of 6 different monoclonal antibodies recognizing $\alpha$-LA in our case.

As illustrated in Figure 8, association and dissociation curves of $\alpha-\mathrm{LA}$ with 2 monoclonal antibodies were shaped similarly for both the initial solution and permeate collected after dead-end UF of the apo- $\alpha$-LA enriched fraction through a $40 \mathrm{~kg} / \mathrm{mol}$ polyacrylonitrile membrane. Intensities were, however, affected by filtration, suggesting an evolution of the antibody accessibility to the antigenic site. As mentioned previously, slight changes in the aqueous environment of proteins ( $\mathrm{pH}$ and ionic strength) can occur during UF but they were supposed to have no effect on immunoassays because of the great dilution applied to samples before measurement of the antigen-antibody interaction. On the contrary, the minor difference in aggregation state between the initial solution and the permeate (because of membrane selectivity) should be responsible for such a result. However, this hypothesis was difficult to verify because the respective specific association sites have not been determined yet for the 6 studied antibodies. According to this example, immunoassays were pointed out to have a high sensitivity that enables the detection of protein modifications occurring during filtration.

\section{Structural Approach for the Validation of Protein Functional Changes}

To confirm the pertinence of the analytical package for filtration-induced modifications, results from our different structural and functional techniques were compared with conventional analyses. The analytical package was first envisaged in crossflow UF without protein transmission to corroborate information that already exists in the literature about some milk proteins. Then, the set of analytical methods was more largely considered in dead-end UF, for which only a few structural results are documented in the case of a $\beta-L G$ solution and none for other globular milk proteins.

Crossflow Filtration Without Protein Transmission. In the case of BSA crossflow UF using a $150 \mathrm{~kg} / \mathrm{mol}$ zirconium oxide membrane, chromatographic data were compared with intrinsic fluorescence measurements. As already explained according to the chromatographic profiles, proteins in the retentate 
A

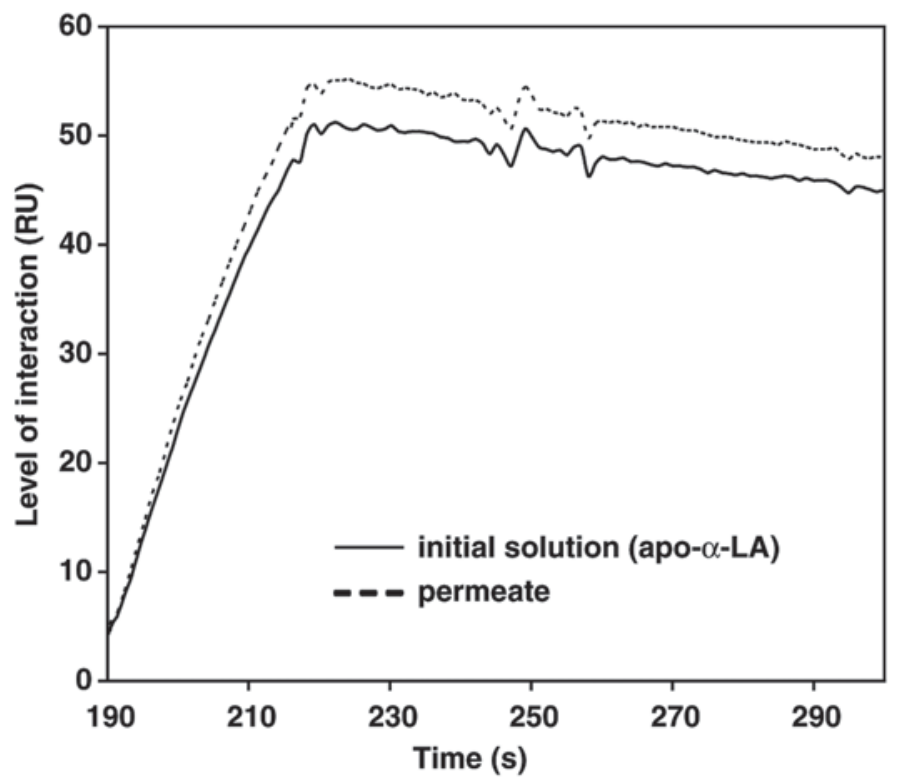

B

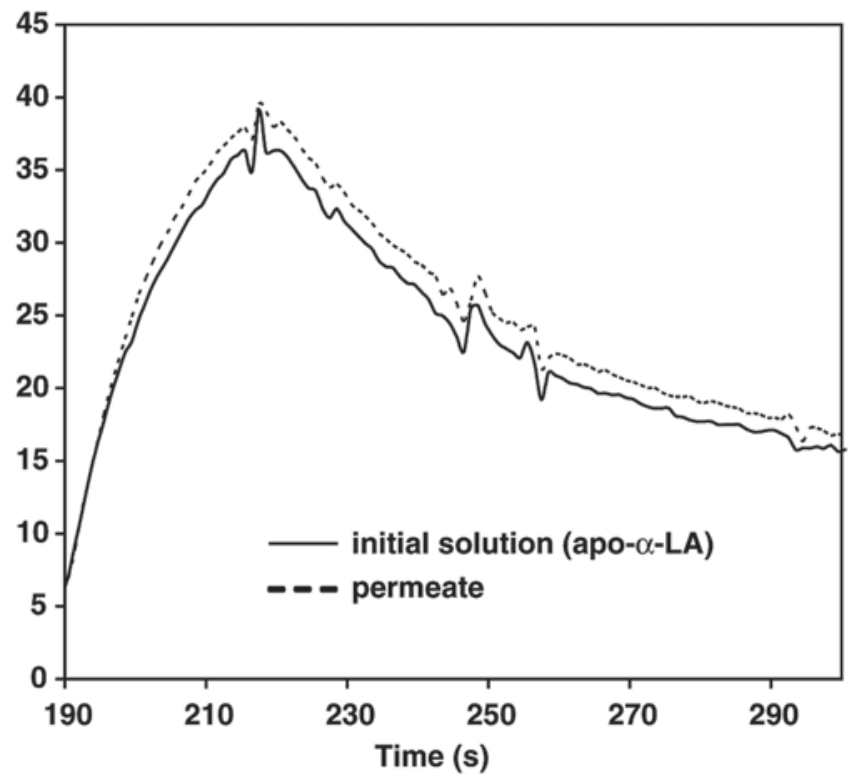

Figure 8. Immunochemistry, a pertinent tool for the detection of filtration-induced modifications. Time-resolved antigenic reaction obtained with the initial apo- $\alpha$-LA enriched solution and the fraction resulting from the dead-end permeation through a $40 \mathrm{~kg} / \mathrm{mol}$ polyacrylonitrile membrane. A) Interaction between $\alpha$-LA and the Mab273 monoclonal antibody. B) Interaction between $\alpha$-LA and the Mab291 monoclonal antibody. $\mathrm{RU}=$ resonance units.

were shown to have a higher propensity to aggregate. Simultaneously, a modification of the intrinsic fluorescence profile was observed: the wavelength of maximum fluorescence intensity was progressively shifted toward lower values (blue shift) and the maximum intensity was significantly decreased (Figures $2 \mathrm{~B}$ and $2 \mathrm{C}$ ). These results corroborated chromatographic observations and suggested a partial aggregation of BSA during circulation in the filtration device. For crossflow UF of a BSA solution without permeation, the comparison of all results proved the pertinence of filtration-induced modifications that were detected. Moreover, it confirmed functional changes described previously by Meireles et al. (1991) in a crossflow mode.

Dead-End Filtration. First, structural and functional observations were examined in the case of $\beta$-LG filtration through a $30 \mathrm{~kg} / \mathrm{mol}$ PES membrane. As mentioned before, the extrinsic fluorescence intensity of $\beta$-LG was increased consecutively to the permeation, suggesting an increase in $\beta$-LG surface hydrophobicity. According to structural analyses, this modification seemed to be linked to a partial protein unfolding. Indeed, the wavelength of maximum intrinsic fluorescence intensity was shifted toward higher values (Figure 3B) and the peak width at half height was increased from $53.4 \pm 0.5 \mathrm{~nm}$ in the initial solution to $57.9 \pm 0.5 \mathrm{~nm}$ in the permeated fraction. These observations were coherent with results of Portugal et al. (2008). At the same time, the wavelength of minimum intensity was shifted toward lower values in far-UV dichroism, suggesting a higher proportion of random coil structure after permeation (Figure 3C). These changes were observed for $\beta$-LG withdrawn in the permeate, whereas no modification was noticed in the retentate after a 7 -h filtration; the intrinsic fluorescence spectrum and the far-UV CD spectrum of $\beta-\mathrm{LG}$ in the retentate were similar to those of $\beta-\mathrm{LG}$ in the initial solution (Figure 3B). As a consequence, we clearly proved that the analytical package enabled the detection of physically induced modifications of proteins because of shear stress inside the membrane pores.

Concerning the dead-end UF of the apo- $\alpha$-LA enriched fraction $(\mathrm{R}=0.36)$ through a $30 \mathrm{~kg} / \mathrm{mol}$ PES membrane, the set of analytical methods was used to validate the effect of permeation on protein characteristics. As previously mentioned, $\alpha$-LA solubility in the permeate was enhanced close to its isoelectric point compared with that of the initial solution and $\alpha$-LA surface hydrophobicity was drastically decreased according to extrinsic fluorescence measurements. These observations were supposed to be generated by a partial conformational change of $\alpha$-LA after permeation. The transition from the apo-form to the holo-form, which is responsible for a change in the protein hydration (Chrysina et al., 2000), could generate higher protein solubility. Moreover, surface hydrophobicity is known to be highly sensitive to $\alpha$-LA conformation: as shown by our results, the binding reaction between ANS and the 
apo-form, which is responsible for the extrinsic fluorescence signal, is not noticed anymore with the holo-form of the protein. The transition from the apo-form to the holo-form of the protein was confirmed by structural analyses; slight conformational changes were noticed using near-UV CD, and the thermal denaturation was shown to be slowed down according to the additional statistical analysis of CD spectra (Figure 6).

The origin of such a phenomenon is difficult to understand, however. Because of the mixture of apo- and holo-forms in the initial solution $(\mathrm{R}=0.36)$, the transition from the apo- to the holo-form could be caused by a partial fractionation between the 2 protein conformations during membrane filtration. The stability of the $\mathrm{Ca}^{2+} / \alpha$-LA ratio at a constant value close of 0.9 to 1.0 in the permeated fraction during the entire filtration is in favor of distinct membrane selectivities toward apo- $\alpha$-LA and holo- $\alpha-L A$. The slight decrease of $R$ in the final retentate could also suggest that the transmission of the holo-form is higher than that of the apo-form of the protein. However, it must be kept in mind that the feed used for filtration experiments is not a mixture between 2 independent proteins. The 2 conformations of the protein are in equilibrium with free calcium and this equilibrium is highly dependent on physicochemical parameters such as protein concentration, $\mathrm{pH}$, and ionic force (Permyakov et al., 1981). Some modifications of this equilibrium could therefore be envisaged in the concentration polarization layer. In our experiment, a significant increase in the molar $\mathrm{Ca}^{2+} / \alpha$-LA ratio was observed close to the membrane at the end of the filtration $(R=0.85)$. According to the association-dissociation reaction between $\alpha$-LA and calcium, such an observation implies an increase in free calcium attributed to the release of calcium from the protein. As a consequence, the holo-form found in the permeate is not necessarily the holo- $\alpha$-LA fraction of the initial solution but could result from a transition of conformation that would occur close to the membrane or during permeation or both. Even if the importance of this second phenomenon is difficult to establish for the UF of $\alpha$-LA using a $30 \mathrm{~kg} / \mathrm{mol}$ PES membrane, its existence was proven with membranes of lower cut-off because a molar $\mathrm{Ca}^{2+} / \alpha$-LA ratio significantly higher than 1.0 was found in the permeate (results not shown). In conclusion, filtration can thus have an indirect effect on $\alpha$-LA properties because of a modification of the equilibrium between apo- and holo-forms. The predominant role of calcium during filtration is confirmed by our functional and structural analyses.

Only a slight difference should be noticed for the interpretation of solubility results. Concerning the change of $\alpha$-LA solubility in the permeate, the increased ratio between other ionic species and $\alpha$-LA could also be incriminated. In the study, it was shown that the higher this ratio, the better the protein solvation and the better the protein solubility. All structural and functional analyses were thus concordant and confirmed the predominant role of calcium for the observed modifications of $\alpha$-LA.

\section{CONCLUSIONS}

In this work, we clearly proved the possibility to study both structural and functional modifications of globular milk proteins (mainly $\alpha-\mathrm{LA}, \beta-\mathrm{LG}$, and BSA) induced by UF. The proposed analytical package was validated for the detection of even slight chemically and physically induced changes according to different original techniques such as CD and RP-HPLC combined with a statistical study, immunochemistry, and functional tests. Results acquired after adaptation of methods (changes in the protocol or improvement of data treatment via statistical methods) were shown to be concordant with those obtained via conventional methods such as fluorescence. Thus, information collected at the macroscopic level was consistent with the data obtained at the molecular level. Furthermore, comparison of all results suggested that chosen techniques were able to distinguish between distinct protein behaviors during filtration processes: globular milk proteins could undergo modifications of distinct origin and intensities during both dead-end and crossflow UF. Following this preliminary study, different perspectives were envisaged, especially the determination of the main operating parameters (such as membrane nature and pore size, transmembrane pressure) responsible for functional and structural modifications during UF of globular milk proteins.

\section{ACKNOWLEDGMENTS}

This work was carried out with the financial support of the Agence Nationale de la Recherche (ANR) under the "Programme National de la Recherche en Alimentation en Nutrition Humaine," project ANR06-PNRA-015. The authors thank V. Lechevalier (UMR1253, Agrocampus Ouest, Rennes, France) for her help with fluorescence experiments, T. Croguennec (UMR1253, Agrocampus Ouest, Rennes, France) and E. Lerumeur (UMR6026, CNRS, Rennes, France) for their advice with circular dichroism measurements, and S. Bugeat (CNIEL, Paris, France) for his kind assistance with statistical computing.

\section{REFERENCES}

Bowen, W. R., and Q. Gan. 1992. Properties of microfiltration membranes: The effects of adsorption and shear on the recovery of an enzyme. Biotechnol. Bioeng. 40:491-497. 
Campbell, M. J., R. P. Walter, R. McLoughlin, and C. J. Knowles. 1993. Effect of temperature on protein conformation and activity during ultrafiltration. J. Membr. Sci. 78:35-43.

Charm, S. E., and C. J. Lai. 1971. Comparison of ultrafiltration systems for concentration of biologicals. Biotechnol. Bioeng. 13:185-202.

Chrysina, E. D., K. Brew, and K. F. Acharya. 2000. Crystal structures of apo- and holo-bovine $\alpha$-lactalbumin at 2.2 - $\AA$ resolution reveal an effect of calcium on inter-lobe interactions. J. Biol. Chem. 275:37021-37029.

Denis, S., S. Terré, Y. Bertheau, and P. Boyaval. 1990. Factors affecting pectate lyase activity during membrane filtration. Biotechnol. Tech. 4:127-132.

Dumon, S., and H. Barnier. 1992. Ultrafiltration of protein solutions on $\mathrm{ZrO}_{2}$ membranes. The influence of surface chemistry and solution chemistry on adsorption. J. Membr. Sci. 74:289-302.

Dupont, D., O. Rolet-Répécaud, and S. Muller-Renaud. 2004. Determination of the heat treatment undergone by milk by following the denaturation of $\alpha$-lactalbumin with a biosensor. J. Agric. Food Chem. 52:677-681.

Elgar, D. F., S. N. Carmen, J. S. Ayers, M. Pritchard, D. E. Otter, and K. P. Palmano. 2000. Simultaneous separation and quantitation of the major bovine whey proteins including proteose peptone and caseinomacropeptide by reversed-phase high-performance liquid chromatography on polystyrene-divinylbenzene. J. Chromatogr. A $878: 183-196$

Geng, X., and F. E. Regnier. 1984. Retention model for proteins in reversed-phase liquid chromatography. J. Chromatogr. 296:1530.

Harris, J. L., M. A. Pecar, and R. J. Pearce. 1989. Effect of the processing equipment on protein functionality in the concentration of cheese whey by ultrafiltration. Aust. J. Dairy Technol. 44:7881.

Herceg, Z., V. Lelas, and A. Režek. 2004. Functional properties of $\alpha$-lactalbumin and $\beta$-lactoglobulin. Mljekarstvo 54:195-208.

International Dairy Federation. 2001. Milk-Determination of nitrogen content-Part 1: Kjeldahl method. FIL-IDF standard 20-1, ISO 8968-1. International Dairy Federation, Brussels, Belgium.

International Dairy Federation. 2002. Dried milk protein productsDetermination of nitrogen solubility index. FIL-IDF standard 173 ISO 15323. International Dairy Federation, Brussels, Belgium.

Jeanson, S., D. Dupont, N. Grattard, and O. Rolet-Répécaud. 1999. Characterization of the heat treatment undergone by milk using two inhibition ELISAs for quantification of native and heat denatured $\alpha$-lactalbumin. J. Agric. Food Chem. 47:2249-2254.

Jolliffe, I. T. 1986. Principal Component Analysis. Springer Verlag, New York, NY.

Kato, A., and S. Nakai. 1980. Hydrophobicity determined by a fluorescent probe method and its correlation with surface properties of proteins. Biochim. Biophys. Acta 624:13-20.

Kella, N. K. D., S. T. Yang, and J. E. Kinsella. 1989. Effect of disulfide bond cleavage on structural and interfacial properties of whey proteins. J. Agric. Food Chem. 37:1203-1210.

Kronman, M. J., R. Andreotti, and R. Vitols. 1964. Inter- and intra-molecular interactions of $\alpha$-lactalbumin. I. The apparent heterogeneity at acid pH. Biochem 3:1145-1160.

Lefèvre, T., and M. Subirade. 1999. Structural and interaction properties of $\beta$-lactoglobulin as studied by FTIR spectroscopy. Int. J. Food Sci. Technol. 34:419-428.

Lemoine, R. 2005. Le lait source de nouvelles promesses. Revue Laitière Française 657:32-33.

Mangino, M. E., L. M. Huffman, and G. O. Regester. 1988. Changes in the hydrophobicity and functionality of whey during the processing of whey protein concentrates. J. Food Sci. 53:1684-1686.

Maruyama, T., S. Katoh, M. Nakajima, and H. Nabetani. 2001. Mechanism of bovine serum albumin aggregation during ultrafiltration. Biotechnol. Bioeng. 75:233-238.
McKenzie, H. A., and W. H. Murphy. 1971. General Methods and Elemental Analysis. Milk Proteins, Chemistry and Molecular Biology. Academic Press, New York, NY.

Mehra, R. K., and W. Donnelly. 1993. Fractionation of whey protein components through a large pore size hydrophilic cellulose membrane. J. Dairy Res. 60:89-97.

Meireles, M., P. Aimar, and V. Sanchez. 1991. Albumin denaturation during ultrafiltration: Effects of operating conditions and consequences on membrane fouling. Biotechnol. Bioeng. 38:528534.

Muller, A., B. Chaufer, U. Merin, and G. Daufin. 2003. Prepurification of $\alpha$-lactalbumin with ultrafiltration ceramic membranes from acid casein whey: Study of operating conditions. Lait 83:111-129.

Narendranathan, T. J., and P. Dunnill. 1982. The effect of shear on globular proteins during ultrafiltration: Studies of alcohol dehydrogenase. Biotechnol. Bioeng. 24:2103-2107.

Permyakov, E. A., V. V. Yarmolenko, L. P. Kalinichenko, L. A. Morozova, and E. A. Burstein. 1981. Calcium binding to alphalactalbumin: Structural rearrangement and association constant evaluation by means of intrinsic protein fluorescence changes. Biochem. Biophys. Res. Commun. 100:191-197.

Portugal, C. A. M., J. G. Crespo, and J. C. Lima. 2007. Monitoring the structural alterations induced in $\beta$-lactoglobulin during ultrafiltration: Learning from chemical and thermal denaturation phenomena. J. Membr. Sci. 300:211-223.

Portugal, C. A. M., J. C. Lima, and J. G. Crespo. 2006. Probing the change of enzymatic activity of horseradish peroxidase induced by membrane permeation using tryptophan fluorescence. J. Membr. Sci. 284:180-192.

Portugal, C. A. M., J. C. Lima, and J. G. Crespo. 2008. Effect of physicochemical conditions on the ultrafiltration of $\beta$-lactoglobulin: Fluorescence probing of induced structural changes. J. Membr. Sci. 321:69-80.

Putnam, F. W. 1975. The Plasma Proteins: Structure, Function and Genetic Control. Vol. 1. F. W. Putnam, ed. Academic Press, New York, NY.

R Development Core Team. 2008. R: A language and environment for statistical computing. R Foundation for Statistical Computing, Vienna, Austria.

Resmini, P., L. Pellegrino, R. Andreini, and F. Prati. 1989 Determinazione delle sieroproteine solubili del latte per HPLC (cromatographia liquida ad alta prestazione) in fase inversa. Sci. Techn. Latt. Cas. 40:7-23.

Roger, L., J. L. Maubois, G. Brulé, and M. Piot. 1981. Process for obtaining an alpha-lactalbumin enriched product from whey, and uses thereof. US Pat. No. 4,485,040.

Themistou, E., I. Singh, C. Shang, S. V. Balu-Iyer, P. Alexandridis, and S. Neelamegham. 2009. Application of fluorescence spectroscopy to quantify shear-induced protein conformation change. Biophys. J. 97:2567-2576.

Towsend, A. A., and S. Nakai. 1983. Relationship between protein hydrophobicity and foaming characteristics of food proteins. J. Food Sci. 48:588-594.

Truskey, G. A., R. Gabler, A. DiLeo, and T. Manter. 1987. The effect of membrane filtration upon protein conformation. J. Parenter. Sci. Technol. 41:180-193.

Vedantham, G., S. L. Carothers, G. Belfort, and T. M. Przybycien. 2003. Structural response of bovine growth hormone to dead-end ultrafiltration. Sep. Sci. Technol. 38:251-270.

Zydney, A. L. 1998. Protein separations using membrane filtration: New opportunities for whey fractionation. Int. Dairy J. 8:243250 . 